\title{
UMA REFLEXÃO SOBRE A CRÍTICA DE HANNAH ARENDT AO CONCEITO DE TRABALHO DE KARL MARX
}

\author{
A Reflection on Hanna Arendt's Criticism towards Karl Marx's Concept of Work
}

Tiago Nilo *

Resumo: O objetivo de tal artigo é suscitar uma reflexão sobre a crítica que Hannah Arendt realiza em A condição humana (1958) ao conceito de trabalho desenvolvido por Karl Marx. Mais especificamente, a crítica que se encontra no capítulo III da obra referida, na qual Arendt critica Marx por ter confundido a atividade do trabalho (labor) com a atividade de fabricação (work). Primeiro, irei expor os argumentos de Arendt contra Marx, para que na sequência, possa realizar uma reflexão sobre eles.

Palavras-chave: Trabalho. Labor. Fabricação. Vida biológica. Animal laborans.

\begin{abstract}
The purpose of this article is to raise a reflection on the criticism that Hannah Arendt held in The Human Condition (1958) the concept of work of Karl Marx. More specifically, the criticism which is in Chapter III of the work in which Arendt criticizes Marx for having confused the work activity (labor) with manufacturing activity (work). First, I will expose Arendt's arguments against Marx, so that as a result, can carry out a reflection on them.
\end{abstract}

Keywords: Work. Labor. Manufacturing. Biological life. Animal laborans.

* Mestre em Filosofia pela Universidade do Vale do Rio dos Sinos. Contato: tnilo@unisinos.br

\begin{tabular}{|c|c|l|l|c|c|}
\hline Intuitio & $\begin{array}{c}\text { ISSN } \\
1983-4012\end{array}$ & Porto Alegre & Vol.9- N $^{\circ} .2$ & $\begin{array}{c}\text { Dezembro } \\
2016\end{array}$ & pp. 88-102 \\
\hline
\end{tabular}




\section{Introdução}

Conforme as estimativas da OIT $^{1}$ existem, em pleno século XXI, mais de doze milhões de pessoas que sofrem com o trabalho escravo em todo o planeta Terra. Conforme tais informações, somente na Ásia e na Oceania, se concentram 9.490 milhões de pessoas nesta situação. A partir destes tristes dados, questionamos o que seja um trabalho livre ou um trabalho envolto na escravidão. Isto é, um trabalho que apenas garanta minha sobrevivência é um trabalho livre? O que é um trabalho livre? O que é um trabalho subjugado? O que é o fenômeno humano do trabalho? O problema do trabalho, seja de ordem semântica ou de sua efetivação historicamente situada, nos insere em tais questões. Pensar a atividade do trabalho de um modo filosófico é um compromisso relevante para a vida que os seres humanos partilham em comum. É evidente que a atividade do trabalho revolucionou a vida dos seres humanos desde o período neolítico até a era digital. Porém, somente na modernidade, mais precisamente na efervescência da Revolução Industrial, é que este fenômeno humano ganhou as devidas atenções teóricas. Obviamente, os acontecimentos históricos contribuíram com isto, caso pensarmos, por exemplo, na passagem da produção artesanal para a manufatureira, e desta, para a produção mecanizada e global até os sistemas de informação e a gestão do conhecimento das organizações contemporâneas. Podemos perceber que a elucidação em torno do significado e da efetividade do trabalho se desviou da reflexão a respeito de tal fenômeno humano para teorias científicas de gerenciamento produtivo, inclusive as famigeradas técnicas motivacionais centradas no capital humano. Estes, talvez, sejam alguns pontos relevantes para pensarmos filosoficamente a respeito da atividade do trabalho. Assim sendo, manifesto que tenho por intuito suscitar uma reflexão sobre a crítica que Hannah Arendt realiza em A condição humana (1958) ao conceito de trabalho desenvolvido por Karl Marx. Mais especificamente, a crítica que se encontra no capítulo III da obra referida, na qual Arendt critica Marx por ter confundido a atividade do trabalho (labor) com a atividade de fabricação (work). Primeiro irei expor tais argumentos para que, na sequência, possa realizar uma reflexão sobre eles.

\section{A indistinção conceitual do termo trabalho como atividade de fabricação e como atividade do labor}

Karl Marx e Hannah Arendt viveram dois momentos históricos diferentes no continente europeu, possuíam, também, referenciais diferentes para se pensar a filosofia política. Conforme a perspectiva arendtiana, na Era Moderna a realização humana se dá no e pelo trabalho, assim, o ideal do ser humano

\footnotetext{
${ }^{1}$ Organização Internacional do Trabalho. Para maior aprofundamento destes dados, conferir www.oitbrasil.org.br ou a revista Nova Escola, ano XXV, n. 231, abril, 2010.
}

\begin{tabular}{|c|c|c|c|c|c|}
\hline Intuitio & $\begin{array}{c}\text { ISSN } \\
1983-4012\end{array}$ & Porto Alegre & Vol.9- $\mathrm{N}^{\mathrm{o} .2}$ & $\begin{array}{c}\text { Dezembro } \\
2016\end{array}$ & pp. 88-102 \\
\hline
\end{tabular}


Uma Reflexão sobre a crítica de Hannah Arendt ao Conceito de Trabalho de Karl Marx

moderno passa a ser o trabalhador e, neste aspecto, segundo ela, Marx fora seu maior teórico². O que está em questão na discussão de Arendt com Marx é uma concepção de ser humano. Para ela, Marx define o ser humano como um animal laborans, um animal trabalhador que realiza esta atividade com o intuito de 'ganhar a vida' e manter a sobrevivência da espécie. Tal concepção reduz o ser humano ao processo biológico da natureza descrevendo tal atividade como um acontecimento natural e não como sendo a criação de um mundo artificial e humano. Ou seja, Marx confundiu, segundo Arendt, Arbeitein e Werken, ponein e ergazesthai, o labore com o facere, o labor e a fabricação. Conforme Hannah Arendt, muitos intelectuais modernos confundiram a atividade do trabalho como labor com a atividade do trabalho como fabricação. Isto se deve ao crescente aumento da produtividade na Era Moderna que, desde a Revolução Industrial, negligenciou tal distinção e elevou o labor à mais digna atividade humana, substituindo, assim, o homo faber (o artesão) pelo animal laborans (o operário) ${ }^{3}$. Tal indistinção, portanto, está fundamentalmente presente na própria natureza da Era Moderna: os objetos de uso perderam a sua durabilidade no mundo e tornaram-se objetos de consumo, assim como ocorrera a glorificação da labuta no processo biológico e o esquecimento do mundo em comum - o processo de produção assume as características da atividade do trabalho como labor. Com a divisão do trabalho, o que é comprado e vendido não é uma qualificação singular, mas a força de trabalho (labor Power) ${ }^{4}$. Assim, a atividade de fabricação fora abandonada em prol da atividade do labor. As máquinas conduzem os seres humanos a um ritmo infinitamente mais rápido de repetição, de movimento ritmado e progressiva aceleração. A exploração da gigantesca produtividade da força humana de labor (labor Power) não diz mais respeito à qualidade ou ao caráter das coisas que ela produz. Tal atividade se fundamenta na manutenção do ciclo vital da humanidade, pois nada possui de durável para o mundo. $\mathrm{E}$ as transformações que se estabeleceram na produção moderna, sacrificaram a durabilidade e a estabilidade em favor da abundância e da felicidade. Os ideais do homo faber foram substituídos pelos ideais do animal laborans - nascia o consumismo e a sociedade de consumidores. Arendt compreende, portanto, que a produção está assentada no "trabalho não-qualificado”, uma característica da atividade do labor. Neste aspecto, o ofício de carpinteiro, por exemplo, não é tão relevante para a produção quanto a “força de trabalho” (labor Power) de um operário 5 . Vejamos, portanto, como Arendt compreende o labor e a fabricação.

\footnotetext{
${ }^{2}$ ARENDT, H. A condição humana. Rio de Janeiro: Forense Universitária, 1997. p. 98.

${ }^{3}$ ARENDT, H. A condição humana. Rio de Janeiro: Forense Universitária, 1997. p. 98.

${ }^{4}$ ARENDT, H. A condição humana. Rio de Janeiro: Forense Universitária, 1997. p. 98.

${ }^{5}$ Com a mudança da produção artesanal para a produção manufatureira e desta para a automatizada, alteraram-se não apenas a quantidade de produtos fabricados, mas, também, a natureza do processo de produção e dos bens produzidos. "Parece que a distinção entre labor e trabalho, que os nossos teoristas tão obstinadamente desprezaram e nossas línguas tão aferradamente conservaram, torna-se realmente apenas uma diferença de grau quando não se leva em conta o caráter da coisa produzida - sua localização, sua função e a duração de sua permanência no mundo. A distinção entre um pão, cuja 'longevidade' no mundo dificilmente ultrapassa um dia, e uma mesa, que pode facilmente sobreviver a gerações de convivas, é sem dúvida muito mais óbvia e decisiva que a diferença entre um
}

\begin{tabular}{|c|c|c|c|c|c|}
\hline Intuitio & $\begin{array}{c}\text { ISSN } \\
1983-4012\end{array}$ & Porto Alegre & Vol.9- No.2 & $\begin{array}{c}\text { Dezembro } \\
2016\end{array}$ & pp. 88-102 \\
\hline
\end{tabular}


Uma Reflexão sobre a crítica de Hannah Arendt ao Conceito de Trabalho de Karl Marx

O labor é pura necessidade, é responsável por suprir as mais imediatas necessidades humanas provenientes do processo biológico. Enquanto que a fabricação é o rompimento com o ciclo natural, é o que possibilita a construção dos objetos, os quais os seres humanos utilizam para construir o seu mundo cultural. A condição humana do labor é a própria vida, pois é uma atividade direcionada para a sobrevivência da espécie, não tendo, portanto, nem fim nem começo determinado ${ }^{6}$. A condição humana da fabricação é a mundaneidade, pois é uma atividade direcionada para a construção de objetos duráveis, condicionada, portanto, pelas categorias de meios e fins. Ela é capaz de produzir um mundo estável de objetos e artefatos duráveis ${ }^{7}$. O que está em jogo na atividade do labor é a sobrevivência, enquanto que a atividade da fabricação gera independência pessoal ${ }^{8}$. Assim, segundo Arendt, a atividade do trabalho como labor e a atividade do trabalho como fabricação são duas atividades distintas, mas que na filosofia de Karl Marx estão homogeneizadas. Isto propiciou a contradição fundamental de todo o seu pensamento. O conceito de trabalho é concebido como uma “eterna necessidade imposta pela natureza”, entretanto, a revolução destina-se a emancipar o ser humano desta mesma atividade ${ }^{9}$. Marx, apesar de definir o ser humano como animal laborans, admite que mesmo a produtividade da atividade do trabalho como labor só tem início com a reificação ${ }^{10}$. Entretanto, ele continuava convicto de que Milton produziu o Paraíso Perdido pela mesma razão que o bicho-da-seda produz seda. ${ }^{11}$. Isto por que, conforme Arendt há uma valorização da vida biológica no pensamento de Marx, tanto na glorificação da produtividade como na ascensão do labor nas atividades humanas. Em ambos os casos encontramos um equacionamento da produtividade com a fertilidade, o trabalho como a reprodução da vida do próprio indivíduo, que lhe garante a sobrevivência e lhe permite a procriação de vida alheia, assegurando, desta forma, a sobrevivência da espécie. Segundo ela, uma das maiores descobertas de Karl Marx foi a "força de trabalho" (labor Power) como mercadoria dispersa no mercado de trabalho. A atividade do trabalho como labor é a produtividade própria, a força humana que não se esgota depois que produz os meios de sua subsistência e que acaba produzindo, portanto, um excedente. A produtividade do labor se preocupa fundamentalmente com os meios da própria reprodução. Assim, a única finalidade da produção é produzir

padeiro e um carpinteiro.” In: ARENDT, H. A condição humana. Rio de Janeiro: Forense Universitária, 1997. p. 105.

${ }^{6}$ Seus produtos são destinados ao consumo, sendo os mais necessários e os menos duráveis, os mais naturais e os menos mundanos, apresentando uma característica essencialmente privada, gregária e alheia ao mundo.

${ }^{7} \mathrm{O}$ labor manifesta-se em uma condição de efemeridade e naturalidade, enquanto que a fabricação, de durabilidade e artificialidade. O labor produz as condições sociais da vida, enquanto que a fabricação forma as condições sociais da durabilidade do mundo.

${ }^{8}$ ARENDT, H. A condição humana. Rio de Janeiro: Forense Universitária, 1997. p. 92-93.

${ }^{9}$ Conforme Arendt, o objetivo da revolução era a emancipação do ser humano em relação ao trabalho. In: ARENDT, H. A condição humana. Rio de Janeiro: Forense Universitária, 1997. p. 143.

${ }^{10}$ Marx utiliza-se, também, do termo vergegensstädlichen para definir o conceito de trabalho, aproximando-o da atividade de fabricação. Entretanto, para Arendt, o que o exercício de tal atividade transforma ainda é matéria-prima e não uma coisa, propriamente dita.

${ }^{11}$ ARENDT, H. A condição humana. Rio de Janeiro: Forense Universitária, 1997. p. 111.

\begin{tabular}{|c|c|l|l|c|c|}
\hline Intuitio & $\begin{array}{c}\text { ISSN } \\
1983-4012\end{array}$ & Porto Alegre & Vol.9- No.2 & $\begin{array}{c}\text { Dezembro } \\
2016\end{array}$ & pp. 88-102 \\
\hline
\end{tabular}


Uma Reflexão sobre a crítica de Hannah Arendt ao Conceito de Trabalho de Karl Marx

ad infinitum objetos de consumo: o princípio da utilidade cede espaço para o princípio da felicidade. Os ideais e valores do animal laborans estão no núcleo da questão, o centro deixa de ser o ser humano (homo faber) e passa a ser a vida biológica (animal laborans). A sociedade humana ou a humanidade socializada de Marx, para Arendt, era justamente a eliminação da lacuna entre existência individual e existência social do ser humano ${ }^{12}$. O ponto de vista social é, tanto na Era Moderna como em Marx, o processo vital da humanidade. A Era Moderna desenvolve o conceito de processo e ratifica a relevância do seu aspecto natural que passa a ser concebido, também, como vital ${ }^{13}$. Segundo Arendt, na Ideologia Alemã (1846) ${ }^{14} \mathrm{a}$ fertilidade do metabolismo do ser humano com a natureza é concebida como sendo o desenvolvimento das forças produtivas. O processo vital, neste caso, é o esforço de reprodução da própria vida e da vida da espécie. O labor Power, portanto, é a característica essencialmente humana ${ }^{15}$. Segundo ela, tais concepções são evidentes na filosofia de Marx, já que ele define tal atividade fisiologicamente ${ }^{16}$, concebendo sua antropologia filosófica como um materialismo naturalista. Materialista por influência dos economistas políticos anglo-saxões e naturalista por parte do evolucionismo de Charles Darwin. Nesta simbiose conceitual, a atividade do trabalho como labor está profundamente relacionada com o metabolismo da natureza, assim, a “[...] emancipação do trabalho, [...] equivale à emancipação da necessidade $[\ldots]^{17}$ ”. Entretanto, a emancipação do labor não elimina o consumo, ao contrário, aumenta-o. Afinal, o processo vital automatizado aumenta a produção que, por sua vez, aumenta o consumo. A Era

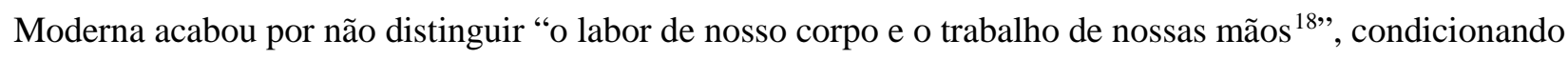
nossa humanidade para a de um animal que labora, “atendendo somente com o corpo as necessidades da vida $^{19}$ ” - escravo da necessidade, como os outros animais ${ }^{20}$. Assim, ela inverteu todas as tradições e substituiu o animal rationale pelo animal laborans. Para Arendt, fora Karl Marx quem enfaticamente pretendia substituir a definição de humano como um animal rationale para o animal laborans. Afinal, Marx afirmou ser o trabalho o elemento criador do ser humano e o fator fundamental que o distinguiu dos outros animais ${ }^{21}$. Conforme Arendt, Marx concebia todo labor como trabalho e falava do animal que

\footnotetext{
12 Aliás, sua categoria de auto-alienação era, justamente, uma alienação do sujeito singular frente a sua natureza social (Gattungswesen).

${ }^{13}$ ARENDT, H. A condição humana. Rio de Janeiro: Forense Universitária, 1997. p. 117.

${ }^{14}$ ARENDT, H. A condição humana. Rio de Janeiro: Forense Universitária, 1997. p. 118.

${ }^{15}$ ARENDT, H. A condição humana. Rio de Janeiro: Forense Universitária, 1997. p. 120.

${ }^{16}$ Conforme Arendt esta definição está evidente nos livros de “O Capital”. In: ARENDT, H. Nota 34. A condição humana. Rio de Janeiro: Forense Universitária, 1997. p.110.

17 ARENDT, H. A condição humana. Rio de Janeiro: Forense Universitária, 1997. p. 143.

18 Alusão à distinção de Locke manifesta por Hannah Arendt em “A condição humana”. In: ARENDT, H. A condição humana. Rio de Janeiro: Forense Universitária, 1997. p. 90.

${ }^{19}$ Referência a Aristóteles manifesta por Hannah Arendt em “A condição humana”. In: ARENDT, H. A condição humana. Rio de Janeiro: Forense Universitária, 1997. p. 90.

${ }^{20}$ Arendt faz referência novamente a Aristóteles na "Política”. In: ARENDT, H. Nota 9. A condição humana. Rio de Janeiro: Forense Universitária, 1997. p. 94.

${ }^{21}$ ARENDT, H. A condição humana. Rio de Janeiro: Forense Universitária, 1997. p. 96-97.
}

\begin{tabular}{|c|c|c|c|c|c|}
\hline Intuitio & $\begin{array}{c}\text { ISSN } \\
1983-4012\end{array}$ & Porto Alegre & Vol.9- N.2 & $\begin{array}{c}\text { Dezembro } \\
2016\end{array}$ & pp. 88-102 \\
\hline
\end{tabular}


Uma Reflexão sobre a crítica de Hannah Arendt ao Conceito de Trabalho de Karl Marx

labora em termos mais adequados ao homem que fabrica ${ }^{22}$, isto por que seu ponto central está na produtividade, na “força humana”, quiçá, especificamente, no excedente que não se esgota depois de produzir os meios de subsistência. O ponto de vista da Era Moderna e de Marx, especificamente, é o social, a sustentação do processo vital da humanidade. Aliás, para Marx, não ter ciência de sua natureza social (Gattungswesen) nada mais é do que auto-alienação, pois, a fertilidade e a abundância são garantidas se a reprodução da vida individual for absorvida pelo processo vital da espécie humana. Assim, a humanidade socializada atenderá a sua própria necessidade ${ }^{23}$, entretanto, Arendt salienta que a fertilidade e a socialização não eliminam o caráter privativo de nosso corpo. Segundo ela, "nem a abundância nem a redução do tempo gasto no labor resultarão no estabelecimento de um mudo comum [... $]^{24 ”}$. O animal laborans socializado e liberto do trabalho goza sua liberdade em atividades estritamente privadas e isoladas do mundo ${ }^{25}$. A humanidade socializada de Marx é uma sociedade de massa de operários da espécie humana isolados do mundo. O animal que labora está preso na privatividade de seu corpo e condicionado por suas necessidades. Reduzem-se, assim, todas as atividades humanas a um determinado fator comum: assegurar as condições necessárias para a manutenção da vida e produzi-las em abundância. Porém, conforme Arendt, “cem anos depois de Marx sabemos o quão falaz é este raciocínio: as horas vagas do animal laborans jamais são gastas em outra coisa senão em consumir [...] $]^{26 ” . ~ O ~}$ resultado da ocupação da atividade do labor na esfera pública é a cultura de massas, isto é, a infelicidade universal, a universal exigência de felicidade e a infelicidade tão comum na sociedade ${ }^{27}$. Para Arendt, a filosofia do trabalho de Marx coincide com o evolucionismo darwinista em relação ao conceito de processo casado com o materialismo econômico. Assim, temos, de um lado, o processo vital de desenvolvimento da vida orgânica, de outro, o desenvolvimento histórico de um processo vital da humanidade ${ }^{28}$. Segundo ela, a introspecção na filosofia e os processos metabólicos nas ciências naturais reforçaram a relevância do processo vital biológico de nosso corpo e do labor como sua atividade correspondente. Assim, o ser humano se distingue dos outros animais não pela imaginação no exercício do ofício, mas, por produzirem seus meios de subsistência ${ }^{29}$.

Passo, portanto, à reflexão de tais considerações.

${ }^{22}$ Segundo Arendt, esta confusão está saliente em "A ideologia alemã” e no terceiro volume de $O$ capital. In: ARENDT, H. Nota 15. A condição humana. Rio de Janeiro: Forense Universitária, 1997. p. 98.

${ }^{23}$ ARENDT, H. A condição humana. Rio de Janeiro: Forense Universitária, 1997. p. 128.

${ }^{24}$ ARENDT, H. A condição humana. Rio de Janeiro: Forense Universitária, 1997. p. 129-130.

${ }^{25}$ ARENDT, H. A condição humana. Rio de Janeiro: Forense Universitária, 1997. p. 143.

${ }^{26}$ ARENDT, H. A condição humana. Rio de Janeiro: Forense Universitária, 1997. p. 146.

${ }^{27}$ Sobre esta "infelicidade universal”: “(...) de um lado a perturbação do equilíbrio entre labor e consumo e, de outro, à persistente exigência do animal laborans de perseguir uma felicidade que só pode ser alcançada quando os processos vitais de exaustão e regeneração, de dor e de alijamento de dor, estão em perfeito equilíbrio.” In: ARENDT, H. A condição humana. Rio de Janeiro: Forense Universitária, 1997. p. 146.

${ }^{28}$ ARENDT, H. A condição humana. Rio de Janeiro: Forense Universitária, 1997. p. 128-129.

${ }^{29}$ ARENDT, H. A condição humana. Rio de Janeiro: Forense Universitária, 1997. p. 111.

\begin{tabular}{|c|c|l|l|c|c|}
\hline Intuitio & $\begin{array}{c}\text { ISSN } \\
1983-4012\end{array}$ & Porto Alegre & Vol.9- No.2 & $\begin{array}{c}\text { Dezembro } \\
2016\end{array}$ & pp. 88-102 \\
\hline
\end{tabular}




\section{REFLEXÕES SOBRE A CRÍTICA DE HANNAH ARENDT AO CONCEITO DE TRABALHO DE KARL MARX}

Além das filosofias divergirem, Marx e Arendt estão distantes também por uma questão histórica ${ }^{30}$, porém, ambas as filosofias políticas podem nos auxiliar a compreender o mundo do trabalho, fundamentalmente, quando propusemos tal tema sob a ótica de uma razão dialógica. Cabe salientar, portanto, que o objetivo de nossa tarefa é essencialmente reflexivo e não (de)finitivo. Isto é, não se trata de decretar ou legitimar um vencedor e um perdedor, mas de refletir sobre o que entendemos quando designamos tal palavra e sobre a condição atual de tal atividade nas relações sociais e humanas. Para facilitarmos a explanação, a crítica de Arendt fora destrinchada em três partes: indistinção entre a atividade do labor e da fabricação, valorização da vida biológica e concepção do ser humano como animal laborans. Meditemos.

Definitivamente não há em Marx uma evidente distinção entre a atividade do trabalho como labor e a atividade do trabalho como fabricação. Ambas as atividades estão reunidas em uma única ideia, trabalho. Isto por que não há, em Marx, separação entre força física de trabalho e força mental de trabalho. As atividades agrícolas, por exemplo, necessitam de um dispêndio mental, assim como físico. De modo semelhante, a atividade de um pintor exige imaginação e habilidades motoras com as mãos. O labor power, isto é, a força humana de trabalho, para Marx, é uma atividade que necessita das faculdades físicas e mentais para ser realizada. Isto por que o físico e o mental fazem parte da matéria, isto é, não há uma dicotomia entre o mundo humano e o mundo natural, o que não significa dizer que ambos coincidem. A questão é mais complexa. Há uma relação dialética entre natureza e realidade humana, onde a realidade social incorpora a natureza ao negá-la. Assim, o conceito de trabalho, em Marx, não é uma atividade estritamente natural, mas um processo social que pressupõe a natureza como sua condição indispensável. Isto é, por mediar, regular e controlar ${ }^{31}$ tal metabolismo, devemos pressupor que haja um elemento teleológico na constituição de tal atividade. O que significa dizer que ela é orientada, sobretudo, por categorias de meios e fins, próprias ao que Hannah Arendt designa por fabricação (work). Além disso, a diferença entre o pior arquiteto e a melhor abelha é de fundamental relevância para que possamos compreender de que modo o ser humano se destaca da esfera das necessidades biológicas, tornando

\footnotetext{
${ }^{30}$ Devemos estar cientes do abismo histórico que há entre as filosofias de Karl Marx e Hannah Arendt. Ele disserta a partir de um século XIX marcado pelo desenvolvimento das ciências naturais, pela ascensão do progresso, pelo desenvolvimento do sistema capitalista industrial e pelo expansionismo do imperialismo nacionalista. Dirigindo-se para o futuro, conserva o otimismo. Ela, um século depois, visualiza uma era marcada pelas experiências totalitárias e pela perda do mundo em comum, a privatização da esfera púbica por parte do labor. Tendo como referência o passado, conserva a cautela.

${ }^{31}$ MARX, K. O Capital. São Paulo: Boitempo, 2013. p. 255.
}

\begin{tabular}{|c|c|c|c|c|c|}
\hline Intuitio & $\begin{array}{c}\text { ISSN } \\
1983-4012\end{array}$ & Porto Alegre & Vol.9- No.2 & $\begin{array}{c}\text { Dezembro } \\
2016\end{array}$ & pp. 88-102 \\
\hline
\end{tabular}


Uma Reflexão sobre a crítica de Hannah Arendt ao Conceito de Trabalho de Karl Marx

determinante o pôr teleológico conscientemente realizado que, “quando parte de fatos corretamente reconhecidos no sentido prático e os avalia corretamente, é capaz de trazer à vida, processos causais ${ }^{32}$ ”. Ao colocar-se, teleologicamente, pressupõe-se que todo processo já esteja idealmente presente na mente do trabalhador. Teleologia e causalidade fazem parte do processo do trabalho. E, neste processo, o ser humano controla ou regula seu metabolismo com a natureza, pois, conforme Marx, agindo “[...] sobre a natureza externa e modificando-a por meio desse desenvolvimento [...] ele modifica, ao mesmo tempo, sua própria natureza ${ }^{33}$ ”. Neste caso, não estamos nos referindo a um animal que labora, o animal laborans de Arendt ou das formas animalescas (tierartig), instintivas do trabalho, conforme Marx, mas de uma apropriação e regulação da matéria a seu próprio domínio, um uso ciente da própria regulação. O processo, portanto, não está imerso no metabolismo, mas naquilo "que diz respeito unicamente ao ser humano 34 ”, isto é, que o distingue dos outros animais, considerado “[...] independentemente de qualquer forma social determinada ${ }^{35}$ ” Tal distinção não é ocasionada pela produção excedente, oriunda do processo de valorização, mas sim, pelo fato de que, no final do processo do trabalho “[...] chega-se a um resultado que já estava presente na representação do trabalhador no início do processo, portanto, um resultado que já existia idealmente. ${ }^{36 ”}$ Assim, entre a causalidade e a teleologia, compõe-se o movimento dialético do devir humano, ou seja, na dialética entre mundo humano e mundo natural, o segundo é incorporado e superado (Aufhebung) pelo primeiro. O mesmo ocorre com o conceito de trabalho. Ele não é abolido, mas incorporado e superado. O ser humano não está imerso em um processo metabólico sem fim, pois o exercício de tal atividade modifica a natureza e a transforma para si, gerando uma realidade social que engloba e modifica a própria natureza ${ }^{37}$. Tanto no O Capital como nos Manuscritos, podemos perceber que a atividade do trabalho não apenas transforma e modifica a natureza como também cria um novo mundo, artificial ${ }^{38}$. A atividade ou o processo do trabalho, portanto, detém características genuinamente humanas, longe de um estrito processo natural. Tal atividade exercida pelos seres humanos não é concebida, portanto, somente em sua relação com a natureza, mas, fundamentalmente, em um contexto histórico-social dado e em dadas condições de vida existentes. Assim, podemos observar que uma coisa é sua forma remunerada na economia nacional, sua manifestação histórica e social, Erwerbstätigkeit ${ }^{39}$. Outra coisa é o elemento ideal que se realiza no processo do facere, como uma ideia, um planejamento,

\footnotetext{
${ }^{32}$ LUKÁCS, G. Prolegômenos para uma ontologia do ser social. São Paulo: Boitempo, 2010. p. 43.

33 MARX, K. O Capital. São Paulo: Boitempo. p. 255.

${ }^{34}$ MARX, K. O Capital. São Paulo: Boitempo. p. 255.

${ }^{35}$ MARX, K. O Capital. São Paulo: Boitempo. p. 255.

${ }^{36}$ MARX, K. O Capital. São Paulo: Boitempo. p. 256.

37 O desenvolvimento deste raciocínio é exposto por Julia Sebba Ramalho, em artigo intitulado, Hannah Arendt versus Marx: uma defesa de Marx frente a crítica arendtiana. In: RAMALHO, J. S. Hannah Arendt versus Marx: uma defesa de Marx frente a crítica arendtiana. Prometeus Filosofia em Revista, ano 2, v.2, n.4, p. 3-6, jul./dez. 2009.

${ }^{38}$ Ver sobre o trabalho alienado. In: MARX, K. Manuscritos econômico-filosóficos. São Paulo: Boitempo, 2008.

${ }^{39}$ MARX, K. Manuscritos econômico-filosóficos. São Paulo: Boitempo, 2008. p. 30
}

\begin{tabular}{|c|c|c|c|c|c|}
\hline Intuitio & $\begin{array}{c}\text { ISSN } \\
1983-4012\end{array}$ & Porto Alegre & Vol.9- N.2 & $\begin{array}{c}\text { Dezembro } \\
2016\end{array}$ & pp. 88-102 \\
\hline
\end{tabular}


Uma Reflexão sobre a crítica de Hannah Arendt ao Conceito de Trabalho de Karl Marx

Vorstellung $^{40}$. Na Era Moderna, a atividade do trabalho como auto-atividade aparece, portanto, como um meio, enquanto que a produção da vida material aparece como um fim. Isto é, são duas diferentes manifestações de uma mesma atividade, que na Era Moderna se encontram separadas ${ }^{41}$. A atividade do trabalho, na Era Moderna, é o trabalho alienado, o animal laborans, pois o operário moderno não transcende o simples fato de estar vivo. Por outro lado, o movimento dialético do conceito nos permite conceber a ideia de um trabalho livre, "uma forma de atividade comparável a atividade lúdica; [...] expressão da auto-realização autônoma ${ }^{42}$ ”. Assim, o trabalho condicionou o ser humano a humanizar o mundo a sua volta e, consequentemente, através do movimento dialético deste processo, o ser humano acabou transformando a sua própria natureza. Para refletirmos sobre tais considerações, tornam-se relevantes não as ciências naturais, mas o processo dialético que capta o “[...] imensamente rico processo de vida ativa [...] $]^{43}$ ”. Isto por que o movimento dialético é atravessado pela atividade do trabalho, a concepção de um ser humano efetivo na qual este ser estabelece as condições de possibilidades de sua existência. O que se percebe não é uma valorização da vida biológica, mas “uma concepção dialética do desenvolvimento histórico real ${ }^{44 ”}$. Materialismo, história e dialética, penso ser necessário indagarmos sobre alguns pontos. Primeiro, tal relação dialética estabelece como condição a priori, a história ou a biologia? Ou, como Arendt busca aproximar e salientar, tanto em Sobre a violência como em Sobre a Revolução, ambos, pois, conforme ela trata-se de uma metafísica política caracterizada por uma simbiose materialista e organicista sintetizada pela noção de processo e que acabara por depositar demasiada confiança no poder da dialética, ocasionando, assim, um preconceito filosófico que se tornou perigoso, como, por exemplo, afirmar que há um bem que advém do mal?

A relação dialética estabelece como condição a priori a ontologia, “[...] a realidade a ser atingida por meio da análise e reconstruída através da exposição é sempre uma realidade em movimento ${ }^{45}$ ”. Tratase, portanto, do devir, onde a matéria é posta em movimento através do trabalho, porém, não “[...] como resultado de um autodesenvolvimento imanente do Valor [...] $]^{46 ”, ~ m a s ~ c o m o ~ u m ~ s a l t o ~ d o ~ p r o d u t o ~ p a r a ~ a ~}$ mercadoria estabelecida na práxis ${ }^{47}$. É, justamente, neste frágil interstício do constante devir que o movimento dialético se desprende de quaisquer pressupostos fatalistas que, por ventura, possam ainda

\footnotetext{
${ }^{40}$ MARX, K. Das Kapital: kritik der politischen Ökonomie. Buch I: Der Produktionsprozeß des Kapitals. In: \& ENGELS, E.: Werke. Berlin: Institut Für Marxismus-Leninismus Bein ZK der sed, 1962. p. 193.

${ }^{41}$ MARX, K. Manuscritos econômico-filosóficos. São Paulo: Boitempo, 2008. p. 73-74.

${ }^{42}$ NEGT, O. O marxismo e a teoria da revolução no último Engels. In: HOBSBAWN, E. História do marxismo: o marxismo na época da segunda internacional. v. II. Rio de Janeiro: Paz e Terra, 1982. p.125-200.

${ }^{43}$ MÉZSÁROS, I. Marx 'filósofo'. In: HOBSBAWM, E. (org.). História do marxismo: o marxismo no tempo de Marx. Rio de Janeiro: Editora Paz e Terra, 1987. p. 177.

${ }^{44}$ MÉZSÁROS, I. Marx 'filósofo'. In: HOBSBAWM, E. (org.). História do marxismo: o marxismo no tempo de Marx. Rio de janeiro: Paz e Terra, 1987. p. 179.

${ }^{45}$ LEFEBVRE, H. Marxismo. Porto Alegre: L\&PM, 2010. p. 32.

${ }^{46}$ ZIZEK, S. A visão em paralaxe. São Paulo: Boitempo, 2008. p. 76.

${ }^{47}$ MARX, K. \& ENGELS, F. A sagrada família. São Paulo: Boitempo, 2011. p. 174.
}

\begin{tabular}{|c|c|l|l|c|c|}
\hline Intuitio & $\begin{array}{c}\text { ISSN } \\
1983-4012\end{array}$ & Porto Alegre & Vol.9- No.2 & $\begin{array}{c}\text { Dezembro } \\
2016\end{array}$ & pp. 88-102 \\
\hline
\end{tabular}


Uma Reflexão sobre a crítica de Hannah Arendt ao Conceito de Trabalho de Karl Marx

buscar legitimação. O movimento dialético da ontologia presente na filosofia marxiana pressupõe, portanto, a contingência e não estrita e unicamente a necessidade. De modo semelhante, faz-se mister não cairmos no que Zizek apontou como os problemas de ontologizar a diferença entre materialismo dialético e materialismo histórico, concebendo-a como “[...] a ontologia universal e sua aplicação ao domínio específico da sociedade. ${ }^{48}$ ” Trata-se de uma mudança fundamental “[...] da reflexão determinada para a determinação reflexiva [...] $]^{49}$ ”, isto é, da noção de polaridade para a de tensão dos polos opostos no movimento dialético. A questão, portanto, não é a harmonia ou a síntese, mas o conflito que reside no próprio movimento dialético. Podemos observar isto na primeira seção do livro I da obra $O$ Capital, na análise sobre o duplo caráter da mercadoria. No início da obra, Marx já adverte que iniciará com a análise da mercadoria no processo de produção do capital, concebendo-a como um objeto externo que satisfaz as necessidades humanas de um tipo qualquer, constituída pela substância do valor de sua utilidade e pela grandeza do seu valor de troca. ${ }^{50}$ Assim, o valor que se cria no processo de produção por meio do trabalho é o valor de uso de um determinado produto que tem a possibilidade de tornar-se uma mercadoria, mas que somente concretizará o seu valor, como valor de troca, quando houver uma equivalência na troca entre as mercadorias, assim, elas “[...] serão reduzidas a algo em comum [...] $]^{51}$ ”, da mesma grandeza. O valor que se cria no processo de produção é potencial, “[...] já que só se concretiza como valor quando a mercadoria produzida é vendida e o círculo D-M-D assim se completa ${ }^{52}$ ”. Em suma, a tensão reside entre os processos de produção e circulação, entre a produção de valor e a sua concretização. Isto é, para ocorrer o devir do produto em mercadoria, “[...] ele tem de produzir não apenas valor de uso, mas valor de uso para outrem, valor de uso social. ${ }^{53}$ " Ou, nas palavras do próprio Marx: "para se tornar mercadoria, é preciso que o produto, por meio da troca, seja transferido a outrem, a quem vai servir como valor de uso. ${ }^{54 ”}$ Assim sendo, o valor gerado em si é substância, valor de uso, enquanto que o valor gerado para si é mensurado no mercado de trocas, detendo um valor de uso, assim como um valor de troca. O valor, portanto, insere-se no produto como potência e concretiza-se como ato na forma da mercadoria. A

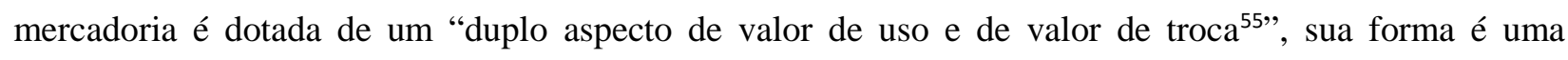
presença universal no interior do modo de produção capitalista, onde o sistema de mercado e a formadinheiro disfarçam as relações reais por meio da troca de coisas. Isto é, as relações sociais “[...] entre as

${ }^{48}$ ZIZEK, S. A visão em paralaxe. São Paulo: Boitempo, 2008. p. 15-16.

49 ZIZEK, S. A visão em paralaxe. São Paulo: Boitempo, 2008. p. 16-17.

${ }^{50}$ MARX, K. O Capital. São Paulo: Boitempo, 2013. p. 113-114.

${ }^{51}$ MARX, K. O Capital. São Paulo: Boitempo, 2013. p. 116.

52 ZIZEK, S. A visão em paralaxe. São Paulo: Boitempo, 2008. p. 76.

${ }^{53}$ MARX, K. O Capital. São Paulo: Boitempo, 2013. p. 119.

${ }^{54}$ MARX, K. O Capital. São Paulo: Boitempo, 2013. p. 119.

${ }^{55}$ MARX, K. Contribuição à crítica da economia política. São Paulo: Martins Fontes, 2011. p. 11.

\begin{tabular}{|c|c|l|l|c|c|}
\hline Intuitio & $\begin{array}{c}\text { ISSN } \\
1983-4012\end{array}$ & Porto Alegre & Vol.9- N $^{\circ} .2$ & $\begin{array}{c}\text { Dezembro } \\
2016\end{array}$ & pp. 88-102 \\
\hline
\end{tabular}


Uma Reflexão sobre a crítica de Hannah Arendt ao Conceito de Trabalho de Karl Marx

pessoas se apresentam por assim dizer como que invertidas, como uma relação social entre as coisas ${ }^{56 ”}$. As relações humanas estão escondidas sob a aparência das coisas e, assim, sob as conciliações. Ocultamse as tensões que residem no próprio movimento do real.

Sem delongas, abordemos outro aspecto desta questão. Ainda sobre o movimento dialético presente na ontologia marxiana, podemos conceber que o materialismo dialético e o materialismo histórico superam a relação entre ser e pensar, superam a relação da ideia como espelho do ser. Isto porque o primeiro concebe o conflito em seu devir e o segundo por meio da noção de consciência como algo inerente do processo de ser (social), de práxis, como processo inserido na realidade social como seu movimento ativo. Vejamos o exemplo da Revolução Francesa e a questão social. Segundo Arendt, por causa da questão social, os revolucionários franceses abandonaram a liberdade em prol da necessidade. Ao invés de fundar a liberdade por meio do estabelecimento sólido de uma constituição, preocuparam-se com a ordem da sociedade e seus problemas sociais. Assim, a carência urgente da população espalhou o terror e conduziu a revolução à ruína. A revolta social foi a substituição das leis artificiais pelas leis naturais. Porém, como a própria Arendt evidencia, há diferenças entre a libertação (como condição da liberdade, mas que não conduz automaticamente a ela) e a liberdade (seja positiva ou negativa). Compreende-se, assim, que para se chegar à liberdade deve-se, necessariamente, percorrer o caminho da libertação, ou seja, libertar-se dos grilhões que o impedem de livremente se locomover ${ }^{57}$. Novamente regressamos ao movimento tensional, à lacuna paralítica entre a libertação do sistema (opressor) e o sistema de liberdade. Os dois exemplos de política revolucionária, o jacobinismo e o bolchevismo, são excelentes, pois é fácil entusiasmar-se com as portas abertas pela revolução, mas é difícil reconhecer, “[...] na Cruz do presente

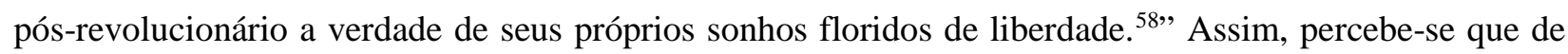
um modo abrangente, a questão social diz respeito a problemas ontológicos que não se limitam tão somente ao metabolismo com a natureza, mas à lacuna inerente à própria humanidade, à pulsão de morte enquanto a paralaxe entre o humano e o inumano. A determinação existente entre o vivo e o morto, o visível e o invisível. O problema não é a passagem do indivíduo para o social, mas saber como a ordem “[...] sócio simbólica extra-impessoal de práticas institucionalizadas e crenças deveria se estruturar quando o sujeito tem de manter sua sanidade, seu funcionamento normal ${ }^{59}$ ”. Percebe-se, neste caso, que o problema é tanto gnosiológico quanto ontológico. Isto é, refere-se tanto ao conhecimento (dividido na produção em nome da especialização) quanto ao “estranhamento” (a alienação em relação aquilo que se

\footnotetext{
${ }^{56}$ MARX, K. Contribuição à crítica da economia política. São Paulo: Martins Fontes, 2011. p. 19.

${ }^{57}$ Neste caso, não estou me restringindo, especificamente, ao conceito de revolução e a problemática existente em relação à ideia de necessidade. $\mathrm{O}$ enfoque será maior em relação ao problema do negativo na dialética marxiana. Ou seja, o exemplo mais significativo, deste modo, não seria sobre a Revolução Gloriosa Inglesa, mas, a relação entre a tirania e o governo legítimo. Cf. ARENDT, H. Sobre a revolução. Lisboa: Relógio D’Àgua Editores, 2001. p. 176.

${ }^{58}$ ZIZEK, S. A visão em paralaxe. São Paulo: Boitempo, 2008. p. 16.

${ }^{59}$ ZIZEK, S. A visão em paralaxe. São Paulo: Boitempo, 2008. p. 17.
}

\begin{tabular}{|c|c|l|l|c|c|}
\hline Intuitio & $\begin{array}{c}\text { ISSN } \\
1983-4012\end{array}$ & Porto Alegre & Vol.9- No.2 & $\begin{array}{c}\text { Dezembro } \\
2016\end{array}$ & pp. 88-102 \\
\hline
\end{tabular}


Uma Reflexão sobre a crítica de Hannah Arendt ao Conceito de Trabalho de Karl Marx

produz e a si mesmo). Esta tensão permite pensar a lacuna de um modo materialista como a diferença mínima, na qual o horizonte não pode ser reduzido a um efeito das ocorrências ônticas, a autopercepção sensorial não pode ser reduzida a um epifenômeno de processos cerebrais objetivos e o antagonismo social não pode ser reduzido a um efeito de coisas socioeconômicas objetivas ${ }^{60}$. Eis, a relevância do (não) negativo na dialética, como definição ele deve expressar “[...] um movimento pelo qual um ser mantém sua identidade pela negação de suas condições ${ }^{61}$ ". Arendt compreendia este velho modelo de pensamento filosófico, um modelo mais antigo do que a própria filosofia grega. O negativo, em Marx, se refere a um locus antitético, uma região tensional e contraditória determinada. A mercadoria, por exemplo, é o devir, o transpassar entre valor de uso e valor. Assim como o valor é o transpassar específico entre a substância do trabalho humano abstrato e sua forma de manifestação que é o valor de troca. O negativo, em Marx, não se refere ao nada, mas à antítese, o polo oposto no movimento tensional. Este choque não ocorre somente entre determinadas categorias conceituais, mas, fundamentalmente, no seio do próprio movimento da matéria, seja no conflito entre as diferentes classes sociais ou na relação entre capital e trabalho. Exatamente por isso que a liberdade gerada pela necessidade, enquanto sobrevivência, não é a partir de um ponto zero, pois o novo é gestado tendo o velho como ponto de partida através da práxis. Não há elementos vitalistas que se coadunam em relações sociais e orgânicas presentes na ontologia marxiana, pois sua investigação se inicia pela produção material ${ }^{62}$, isto é, suas análises são baseadas em pressupostos materialistas extraídos de um determinado sistema econômico. Não há, portanto, na filosofia de Karl Marx um impulso vital de natureza imaterial, diferente das forças físicas ou das interações físicoquímicas reconhecidas. Ou seja, não há um vitalismo.

De modo semelhante, segundo Arendt, há, na filosofia de Marx, uma substituição que pretende remover a tradicional concepção antropológica do animal racional pelo animal que labora. Entretanto, almejo ponderar um pouco mais sobre esta questão. O sujeito do conhecimento, na filosofia de Karl Marx não é a consciência individual isolada. O que, por outro lado, não significa negar a sua existência, sua particularidade. E, muito menos, concebê-la unilateralmente em sua animalidade. Para compreendermos a ideia de Gattungswesen expressa na filosofia de Marx devemos retomar sua crítica à Feuerbach. Conforme este pensador, a essência humana está contida "somente na comunidade, na unidade do homem com o homem, uma unidade que se apoia apenas na realidade da diferença entre Eu e Tu³". Isto é, para ele, cada singularidade humana contém em si o gênero humano. Ideia, esta, absorvida por Marx, mas que, segundo

${ }^{60}$ ZIZEK, S. A visão em paralaxe. São Paulo: Boitempo, 2008. p. 18.

${ }^{61}$ MARCUSE, H. Razão e Revolução: Hegel e o advento da teoria social. Rio de janeiro: Terra e Paz, 1978. p. 78.

62 Referência ao início da introdução dos manuscritos de 1857-1858, quando Marx busca estudar sobre a relação entre produção, consumo, distribuição e troca (circulação) na produção capitalista. Ver: MARX, K. Grundrisse. São Paulo: Boitempo, 2011.

${ }^{63}$ MARX, K. \& ENGELS, F. A Ideologia Alemã: crítica da mais recente filosofia alemã em seus representantes, Feuerbach, Bruno Bauer e Stirner, e do socialismo alemão em seus diferentes profetas. São Paulo: Boitempo, 2007. p. 79.

\begin{tabular}{|c|c|l|l|c|c|}
\hline Intuitio & $\begin{array}{c}\text { ISSN } \\
1983-4012\end{array}$ & Porto Alegre & Vol.9- No.2 & $\begin{array}{c}\text { Dezembro } \\
2016\end{array}$ & pp. 88-102 \\
\hline
\end{tabular}


Uma Reflexão sobre a crítica de Hannah Arendt ao Conceito de Trabalho de Karl Marx

Marx, ainda estava imersa na teoria, na generalização da espécie. Tanto para Feuerbach quanto para Marx, a matéria precede a ideia. Entretanto, no primeiro, a essência humana é manifesta pela abstração, enquanto que, no segundo, ela é manifesta na efetividade humana, como conjunto das relações sociais ${ }^{64}$. Para ambos, ser humano significa pertencer à humanidade, ao gênero humano. A humanidade socializada busca conciliar os direitos do homem e os direitos do cidadão, promovendo, assim, a emancipação humana. Neste caso, não se trata, única e necessariamente, de garantir a sustentação do processo vital da espécie, mas de redefinir e fundamentar a liberdade não como uma limitação que há entre um ser humano e outro, onde este outro não é realização de minha liberdade, mas a restrição dela ${ }^{65}$. Compreende-se, então, que a fantasia das robinsonadas do século XVIII, para Marx, corresponde aos argumentos favoráveis à linguagem privada, já que a produção do singular “[...] isolado fora da sociedade [...] é tão absurda quanto o desenvolvimento da linguagem sem indivíduos vivendo juntos e falando uns com os outros. ${ }^{66 ”}$ Talvez, poderíamos acrescentar os pressupostos biopolíticos sobre a atomização do homo oeconomicus ${ }^{67}$ como

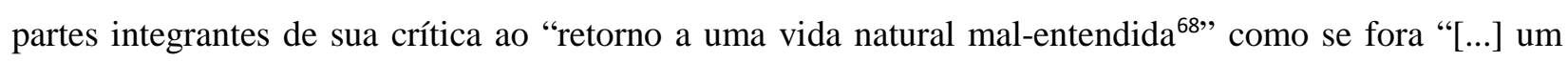
ideal cuja existência estaria no passado. Não como um resultado histórico, mas como ponto de partida da história. Visto que o indivíduo natural [...] não se origina na história, mas é posto pela natureza. ${ }^{69,}$

Não anseio ser categórico em minhas afirmações, porém, presumo que, talvez seja questionável a afirmação de que haveria na filosofia marxiana, um intento para substituir a condição humana da ratio pela condição natural do animal que labora em sua antropologia filosófica. Ao contrário, parece-me evidente que Marx era crítico à naturalização do discurso econômico que pretendia camuflar o caráter fetichista que obscurecia as relações sociais. Mais uma vez, nota-se que Marx percebia a relação tensional entre o indivíduo isolado e sua época ${ }^{70}$, uma relação de conflito e não de conciliação que é próprio à concepção marxiana do movimento dialético. Ressalto o fato de que demonstrar a relevância do social não corresponde, necessariamente, a um desmerecimento ou a um descaso para com a particularidade. Ou seja, falar em igualdade e liberdade não implica, necessariamente, em reduzir-se a uma uniformidade. Marx não

\footnotetext{
${ }^{64}$ MARX, K. \& ENGELS, F. A Ideologia Alemã: crítica da mais recente filosofia alemã em seus representantes, Feuerbach, Bruno Bauer e Stirner, e do socialismo alemão em seus diferentes profetas. São Paulo: Boitempo, 2007. p. 538.

${ }^{65}$ MARX, K. Sobre a questão judaica. São Paulo: Boitempo, 2010. p. 49.

${ }^{66}$ MARX, K. Grundrisse. São Paulo: Boitempo, 2011. p.40.

67 Este, talvez, seja um ponto interessante entre Marx e Foucault. A governabilidade das subjetividades no nascimento da biopolítica, sobretudo no discurso econômico, do sujeito de interesses ao investidor de si, expostos em cursos no Collège de France entre 1978 e 1979 (Ver: FOUCAULT, M. Nascimento da biopolítica. São Paulo: Martins fontes, 2008) lembram o ponto de vista do indivíduo isolado, manifesto por Marx no início dos Grundrisse (Ver: MARX, K. Grundrisse. São Paulo, Boitempo, 2011. p. 40.). Entretanto, não tenho por interesse aprofundar sobre tal questão, pois, isto ampliaria demasiadamente o horizonte da reflexão e comprometeria nosso objetivo. A relação foi trazida à tona como um recurso alusivo na problematização do tema.

${ }^{68}$ MARX, K. Grundrisse. São Paulo:Boitempo, 2011. p. 39.

${ }^{69}$ MARX, K. Grundrisse. São Paulo: Boitempo, 2011. p. 40.

${ }^{70}$ MARX, K. Grundrisse. São Paulo: Boitempo, 2011. p. 40.
}

\begin{tabular}{|c|c|c|c|c|c|}
\hline Intuitio & $\begin{array}{c}\text { ISSN } \\
1983-4012\end{array}$ & Porto Alegre & Vol.9- N.2 & $\begin{array}{c}\text { Dezembro } \\
2016\end{array}$ & pp. 88-102 \\
\hline
\end{tabular}


se atém ao ser humano no singular, do humano, mas, nas suas relações sociais, em conjunto, da vida em comum, da convivência. De modo semelhante, ele não se limita às relações políticas, mas foca-se nas produtivas.

Certamente, as considerações arendtianas problematizam e nos fazem refletir sobre a filosofia de Marx, assim como esboçam ou desenham alguns limites manifestos pela filosofia deste pensador. Algo perfeitamente natural para um ser humano como todos nós. Mas, de certa forma, a análise arendtiana a respeito do conceito de trabalho de Karl Marx parece estar embebida nos pressupostos marxistas da socialdemocracia alemã do início do século XX. Minha pressuposição baseia-se no fato de que a leitura da filosofia marxiana por parte de Arendt parece, profundamente, semelhante à ótica exposta no AntiDuring $^{71}$ de Friedrich Engels - obra que influenciou o marxismo social-democrata alemão. De fato, não encontramos nenhuma citação de tal obra de Engels presente como referência utilizada para a composição, especificamente, de A condição humana (1958). Entretanto, suas análises em relação à filosofia de Karl Marx são semelhantes àquelas disseminadas por tais filosofias marxistas anteriormente mencionadas. Atrevo-me a presumir que isto se deve ao fato de que em sua análise as concepções mecanicistas e organicistas da filosofia de Marx decorrem do positivismo do século XIX e seu legado cientificista para o século precedente. De qualquer modo, é inegável sua negligência para com a filosofia da práxis e a ausência na abordagem dialética sobre o conceito de trabalho presente na filosofia de Marx. Conforme podemos observar, Arendt acabara por preterir a dinâmica conceitual da filosofia de Marx, concebendo-a como sendo confusa e que seria melhor revelada caso os conceitos fossem fragmentados, compartimentados e catalogados dentro de uma estrutura semântica diferenciada ${ }^{72}$. Entretanto, isto descaracterizaria a análise e a própria concepção filosófica dele. Compreende-se, portanto, que a leitura e a ótica desferida por Arendt ao conceito de trabalho de Karl Marx estão limitadas e condicionadas a uma interpretação histórica que negava a práxis e o movimento dialético em nome da necessidade e do determinismo naturalista. Por fim, considero relevante ressaltar que o propósito deste artigo consistiu, portanto, em analisar e refletir sobre algumas interpretações de Hannah Arendt a respeito do conceito de trabalho na filosofia de Karl Marx. Ratifico que nosso interesse não foi o de provar a veracidade de um e a falsidade de outro, mas sim, provocar uma reflexão, trazer à luz alguns questionamentos e produzir um profícuo aprofundamento para a filosofia política.

\footnotetext{
${ }^{71}$ ENGELS, F. Anti-Düring. São Paulo: Boitempo, 2015.

72 YOUNG-BRUEHL, E. Por amor ao mundo: a vida e a obra de Hannah Arendt. Rio de Janeiro: Relume-Dumará, 1997. p. 255.
}

\begin{tabular}{|c|c|c|c|c|c|}
\hline Intuitio & $\begin{array}{c}\text { ISSN } \\
1983-4012\end{array}$ & Porto Alegre & Vol.9 $-\mathrm{N}^{\circ} .2$ & $\begin{array}{c}\text { Dezembro } \\
2016\end{array}$ & pp. 88-102 \\
\hline
\end{tabular}




\section{Referências}

ARENDT, H. Origens do totalitarismo. São Paulo: Companhia das letras, 1989. 562p. . A condição humana. 8. ed. Rio de Janeiro: Forense Universitária, 1997. 352p.

. Sobre a Revolução. Lisboa: Relógio d’água, 2001. 398p.

. Sobre a violência. São Paulo: Companhia das letras, 2009. 167p.

. Entre o passado e o futuro. São Paulo: Perspectiva, 2005. 348p.

ENGELS, F. Anti-Düring. São Paulo: Boitempo, 2015. p. 160-177.

FOUCAULT, M. Nascimento da biopolítica. São Paulo: Martins fontes, 2008. 474p.

KRADER, L. Evolução, revolução e Estado: Marx e o pensamento etnológico. In: HOBSBAWM, E. (org.). História do marxismo: o marxismo no tempo de Marx. Rio de Janeiro: Editora Paz e Terra, 1987. 314p.

LEFEBVRE, H. Marxismo. Porto Alegre: L\&PM, 2010. 127p.

LUKÁCS, G. Prolegômenos para uma ontologia do ser social. São Paulo: Boitempo, 2010. p. 43

MARCUSE, H. Razão e Revolução: Hegel e o advento da teoria social. Rio de janeiro: Terra e Paz, 1978. p. 69-79.

MARX, Karl. Manuscritos econômico-filosóficos. São Paulo: Boitempo, 2008. 175p.

. Sobre a questão judaica. São Paulo: Boitempo, 2010.139p.

. Contribuição à crítica da economia política. São Paulo: Martins Fontes, 2011. p. 3-59.

. Grundrisse. São Paulo: Boitempo, 2011. p. 27-44.

. O Capital. São Paulo: Boitempo, 2013. p. 113-119.

. Das Kapital: kritik der politischen Ökonomie. Buch I: Der Produktionsproze $\beta$ des Kapitals. In: \& ENGELS, F. : Werke. Berlin: Institut Für Marxismus-Leninismus Bein ZK der sed, 1962.768p.

. \& ENGELS, F. A Ideologia Alemã. São Paulo: Boitempo, 2007. 616p.

. A Sagrada família. São Paulo: Boitempo, 2008. 286p.

MÉZSÁROS, I. Marx 'filósofo'. In: HOBSBAWM, E. (org.). História do marxismo: o marxismo no tempo de Marx. Editora Paz e Terra: Rio de Janeiro, 1987.

NEGT, O. O marxismo e a teoria da revolução no último Engels. In: HOBSBAWN, E. História do marxismo: o marxismo na época da segunda internacional. v. II. Editora Paz e Terra: Rio de Janeiro, 1982.

RAMALHO, J. S. Hannah Arendt versus Marx: uma defesa de Marx frente a crítica arendtiana. Prometeus Filosofia em Revista, ano 2, v.2, n.4, p. 3-6, jul./dez. 2009.

SALVADORI, M. L. Kautsky entre a ortodoxia e o revisionismo. In: HOBSBAWN, E. História do marxismo: o marxismo na época da segunda internacional. v.II. Editora Paz e Terra: Rio de Janeiro, 1982.

YOUNG-BRUEHL, E. Por amor ao mundo: a vida e a obra de Hannah Arendt. Rio de Janeiro: RelumeDumará, 1997. p. 255.

ZIZEK, S. A visão em paralaxe. São Paulo: Boitempo, 2008. p. 13-99.

Recebido em: 6 de maio de 2015.

Aprovado para a publicação em: 3 de outubro de 2016.

\begin{tabular}{|c|c|l|l|c|c|}
\hline Intuitio & $\begin{array}{c}\text { ISSN } \\
1983-4012\end{array}$ & Porto Alegre & Vol.9- No.2 & $\begin{array}{c}\text { Dezembro } \\
2016\end{array}$ & pp. 88-102 \\
\hline
\end{tabular}

